\title{
EVOLUCIÓN DEL DERECHO PROCESAL CIVIL EN EUROPA: CÓMO EL JUEZ ACTIVO SE CONVIRTIÓ EN LO NORMAL
}

\author{
EVOLUTION OF CIVIL PROCEDURAL LAW IN EUROPE: HOW THE ACTIVE JUDGE \\ BECAME THE NORM
}

C.H.VAN RheE ${ }^{*}$

Fecha Recepción: 18/10/2011

Fecha Aprobación: 18/11/2011

\begin{abstract}
Resumen:
El presente artículo discute el desarrollo del derecho procesal civil en varias jurisdicciones europeas desde el inicio del siglo XIX hasta hoy. El tema central es el cambio de la posición del juez, desde un árbitro imparcial a un administrador activo de casos. Las jurisdicciones bajo discusión son Francia, Austria, Suiza, Bélgica, los Países Bajos, Inglaterra y Gales.
\end{abstract}

Palabras clave: Procedimiento Civil, Litigación Civil, Administración Judicial de Casos, Juez Director del Proceso
Abstract:
The present article discusses the development of civil procedural law in sev- eral European jurisdictions from the start of the nineteenth century until the present. The central theme is the change in the position of the judge, from a passive umpire into an active case manager. The jurisdictions under discus- sion are France, Austria, Switzerland, Belgium, the Netherlands and England \& Wales.

Key words: Civil Procedure, Civil Litigation, Judicial Case Management, Managerial Justice 


\section{Introducción}

La cooperación europea ha traído como consecuencia una serie de oportunidades nuevas y desafiantes para los académicos del derecho quienes, desde el denominado 'período de codificación' - el cual comenzó en la segunda mitad del siglo XVIII y que, para Alemania, terminó a fines del siglo XX con la introducción del Código Civil Alemán- se han acostumbrado a actuar dentro de un contexto puramente nacional. Esto se aplica incluso a los estudiantes del procedimiento civil, quienes durante un período de tiempo considerable se han resistido a abandonar dicho contexto. El artículo sexto de la Convención Europea de Derechos Humanos (COEDH) y la jurisprudencia de la Corte Europea de Derechos Humanos se constituyen hoy como hitos de importancia primordial en este contexto. De cierto modo, la jurisprudencia de la Corte sirve de guía para develar las tradiciones europeas del procedimiento civil, debido a que a menudo ella justifica sus decisiones estableciendo la concordancia de las mismas con dichas tradiciones. Al mismo tiempo, esta jurisprudencia puede servir de base para nuevas tradiciones puesto que tiende a influenciar tanto a la legislación de los Estados sujetos a su jurisdicción, como también a la interpretación de dicha legislación por las cortes nacionales. Un ejemplo evidente de ello es la jurisprudencia de la Corte concerniente a la administración de justicia dentro de un tiempo razonable.

Aparte del artículo sexto de la Convención Europea de Derechos Humanos y la jurisprudencia de la Corte Europea de Derechos Humanos, el procedimiento civil también está adquiriendo una perspectiva europea como resultado de la creciente influencia de la Unión Europea en este ámbito ${ }^{1}$. Una serie de Reglamentos europeos ${ }^{2}$, directivas ${ }^{3}$, y Green Papers ${ }^{4}$ sobre materias procesales, como también el artículo 81 del Tratado de Funcionamiento de la Unión Europea ${ }^{5}$, y la jurisprudencia de la Corte

1 No voy a tratar la evolución en el marco de la Asociación Europea de Libre Comercio (EFTA) ni los convenios elaborados por la Conferencia de La Haya sobre procedimiento civil, claro que lo último no se limita a Europa.

2 Por ejemplo, Reglamento № 1346/2000de 29 de mayo de 2000, sobre procedimientos de insolvencia; Reglamento $N^{\circ} 44 / 2001$ de 22 de diciembre de 2000, relativo a la competencia judicial, el reconocimien-

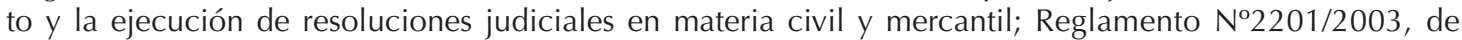
27 denoviembre de 2003 relativo a la competencia, el reconocimiento y la ejecución de resoluciones judiciales en materia matrimonial y de responsabilidad parental, Reglamento №1393/2007, de 13 de noviembre de 2007 relativo a la notificación y al traslado en los Estados miembros de documentos judiciales y extrajudiciales en materia civil o mercantil.

3 Por ejemplo,la Directiva del Parlamento Europeo y del Consejo de 29 de junio de 2000 por la que se establecen medidas de lucha contra la morosidad en las operaciones comerciales (2000/35/CE, 29 de junio de 2000).

4 Green Paper es una publicación oficial de la unión europea que pone en debate temas específicos, y luego indica posibles cursos de acción en términos de política y legislación a nivel europeo (N.del.T).

5 Anteriormente artículo 65 del Tratado Constitutivo de la Comunidad Europea. 
Europea de Justicia, recaen directamente en aspectos procesales. Es evidente que hemos recorrido un largo camino desde aquellos días en que el procedimiento civil era visto como una rama meramente nacional del derecho. En mi opinión, no es improbable que en el futuro el artículo 81 -o sus sucesores- también sea de importancia para determinados casos que actualmente son calificados como puramente nacionales ${ }^{6}$.

A la luz del desarrollo previo, las iniciativas para estudiar el procedimiento civil han sido tomadas desde una perspectiva europea con la finalidad de lograr una posterior armonización del derecho procesal civil en Europa. Por supuesto, el ejemplo más notorio es la iniciativa tomada por el denominado Grupo Storme, el cual ha formulado un conjunto de reglas comunes para el procedimiento civil europeo ${ }^{7}$. Aunque se han formulado observaciones críticas en lo que respecta a estas reglas ${ }^{8}$, la iniciativa Storme sigue siendo importante. Esto no es menor, ya que dentro del marco europeo, fue el primero de su tipo y hasta ahora el único9. El desarrollo europeo en el campo del procedimiento civil, la iniciativa Storme y las observaciones críticas efectuadas a la iniciativa, dejan en claro la importancia de los estudios académicos sobre la naturaleza y los principios subyacentes a los diversos sistemas procesales de la Unión Europea. Estos estudios son escasos, especialmente aquellos que intentan compren-

6 Ver, por ejemplo Van Rhee, C.H., 'Het burgerlijk procesrecht: een historisch fenomeen met toekomstperspectief', Tijdschrift voor Privaatrecht, 2003, pp. 841-870.

7 Storme, M. (ed.), Rapprochement du droit judiciaire de I'Union européenne/Approximation of Judiciary Law in the European Union, Nijhoff, Dordrecht [etc.], 1994. Véase también Van Rhee, C.H., y Coenraad, L., 'Jurist zonder grenzen: interview met M.L.L.V. Storme', en Veen, Th., et al. (ed.), Prominenten kijken om. Achttien rechtsgeleerden uit de Lage Landen over leven, werk en recht (= Pro Memorie. Bijdragen tot de rechtsgeschiedenis der Nederlanden 2004), Verloren, Hilversum, 2004, pp. 155-158.

8 En particular Rouhette, G., 'Sur I'harmonisation du droit du procès civil au sein de l'Union européenne', Justices - Revue générale de droit processuel, 1995, pp. 365-373; Lindblom, P.H., 'Harmony of Legal Spheres. A Swedish view on the construction of a unified European procedural law', European Review of Private Law, 1997, pp. 11-46.

9 En una escala mundial, una iniciativa hecha por el Instituto Americano de Derecho (IAD) y el Instituto Internacional para la Unificación del Derecho Civil (UNIDROIT) se ha traducido en Principios y Reglas del Procedimiento Civil Transnacional. Sobre estos Principios y Reglas, ver Chorus, J.M.J., 'Het Interim-Rapport en Europa en de wereld', en P. Ingelse (ed.), Commentaren op fundamentele herbezinning (= Prinsengrachtreeks 2004-1), Ars Aequi Libri, Nijmegen, 2004, pp. 25 y ss. Para observaciones muy críticas de este anteproyecto, ver Fouchard, Ph. (ed.), Vers un procès civil universel? Les règles transnationales de procédure civile de I'American Law Institute, Pantheon-Assas, L.G.D.J. diffuseur, Paris, 2001. Para un anteproyecto más reciente de Principios y Reglas, ver Ferrand, F. (ed.), La procédure civile mondiale modélisée, Editions juridiques et techniques, collection Droit et Procédures, Paris, 2005. El anteproyecto trata de seguir un camino intermedio entre el procedimiento civil angloamericano y el continental. Se inició como resultado de la convicción de que las diferencias en el procedimiento civil dificultan el comercio internacional. 
der los procedimientos civiles en Europa ${ }^{10}$ desde una perspectiva histórica, lo que no debe ser confundido con el procedimiento civil europeo. Por consiguiente, he tomado como mi estrella guía a la perspectiva histórica ${ }^{11}$, pues me he concentrado en el desarrollo de Francia, Los Países Bajos, Alemania, Austria, Suiza, e Inglaterra durante el siglo XIX, XX y los primeros años del siglo XXI.

En el campo del derecho comparado, hoy en día ya no está en boga tomar como punto de partida las Ilamadas 'familias legales' y se ha vuelto común cuestionarse incluso la distinción entre las tradiciones del civil y Common Law. Así como ya tampoco es políticamente correcto, en estos días, considerar determinadas tradiciones jurídicas nacionales. No obstante, creo que se justifica hacerlo, porque después de todo este artículo está dirigido a los académicos del derecho que no están -o están someramente- familiarizados con el pasado legal compartido de los distintos sistemas de procedimiento civil que existen hoy en día en Europa. Para los académicos, el agrupar estos sistemas legales dentro de las denominadas familias legales, puede servir como una importante herramienta heurística y ello se reafirma porque la historia del procedimiento civil en Europa difiere en un grado significativo de la historia del derecho substantivo privado, el cual puede resultar más familiar para el estudiante de derecho promedio.

\section{El éxito del código de procedimiento civil francés de $\mathbf{1 8 0 6}$ en el siglo XIX}

No es una declaración demasiado atrevida el decir que la historia del procedimiento civil moderno en Europa continental comienza con el código de procedimiento civil francés de 1806, el cual entró en vigencia en 1807. Fue el hermano menor del igualmente influyente Code civil, que serviría como modelo para un sinnúmero de otras codificaciones en Europa -y más allá- en el campo del procedimiento civil. Esto puede sorprendernos porque, mirado como un conjunto, el código de procedimiento francés no era muy moderno; y como señala Alain Wijffels ${ }^{12}$, fue de hecho

10 El Procedimiento Civil Europeo incluye el procedimiento de las diversas Cortes Europeas (por ejemplo, el Tribunal Europeo de Justicia, la Corte Europea de Derechos Humanos) así como también las reglas sobre temas procesales que se originan a nivel europeo en vez de a nivel nacional. El procedimiento civil en Europa se concentra en el estudio comparativo de diferentes procedimientos nacionales de los países europeos.

11 Un ejemplo claro es Van Caenegem, R.C., 'History of European Civil Procedure' en, Cappelletti, M. (ed.), Civil Procedure, Vol. XVI International Encyclopedia of Comparative Law, Chapter 2, J.C.B. Mohr, Tübingen [etc.], 1971.

12 Wijffels, A., 'French Civil Procedure (1806-1975)', en Van Rhee, C.H. (ed.), European Traditions in Civil Procedure, Intersentia, Antwerpen - Oxford, 2005, pp. 25-47. 
uno de los Códigos Napoleónicos menos innovadores, puesto que en gran medida incorporaba el derecho procesal civil tal como podía ser encontrado en la Ordenanza Real de procedimiento civil de Colbert del año 1667 promulgada bajo el imperio de Luis XIV. No obstante, dos razones contribuyeron a la popularidad alcanzada por el código francés. Primero, su modelo procesal se tornó familiar para los abogados en diferentes lugares de Europa debido al hecho que había sido introducido a esos territorios como resultado de la expansión del imperio francés y a su esfera de influencia a fines del siglo XVIII y a comienzos del siglo XIX. En muchos casos constituyó el primer acercamiento que tuvieron los abogados con un sistema codificado de derecho procesal civil y sus ventajas. Además, aunque el Código fue bastante conservador en varios aspectos, también fue un código moderno. Era novedoso en cuanto a que su estructura general reflejó un intento por crear un patrón general de procedimiento, pero al mismo tiempo ajustarlo para el cumplimiento de requerimientos específicos. El patrón general era visto por el legislador como ley general del procedimiento, del cual solo derivó para luego dar cabida a las reglas requeridas para satisfacer necesidades o intereses específicos. Al mismo tiempo, el énfasis del código en la oralidad y publicidad lo convirtió en un código moderno ante los ojos de abogados habituados al procedimiento escrito y relativamente secreto característico del período del lus Commune. El hecho de que este procedimiento reflejara la actitud liberal del siglo XIX, con su énfasis en la responsabilidad individual de los ciudadanos considerados como hombres razonables que litigarían unos contra otros en una posición de igualdad, fue otro rasgo del código que calzó bien en la Europa del siglo XIX. Como resultado de ello, no fue muy acentuado el poder del tribunal para intervenir en el proceso del litigio en pos de la eficiencia y con el fin de prevenir el retraso excesivo. Para dar solo un ejemplo, del código no aparece que el juez tuviese los medios para forzar a las partes a poner sus 'cartas sobre la mesa' en una etapa temprana del juicio. Por el contrario, en la mayoría de los casos se le dio a las partes la oportunidad para hacer sus alegaciones incluso hasta el final de la última audiencia oral. Tampoco fue restrictivo en cuanto a la posibilidad de introducir nuevas alegaciones en la apelación. Esto fue al mismo tiempo uno de los aspectos más conservadores del código, puesto que la autonomía de la parte yace en la base de distintos modelos procesales de principios de la Europa moderna ${ }^{13}$.

No obstante, se hace necesaria una advertencia, Franz Klein, el padre del Código de Procedimiento Civil austriaco de 1895 que anunciaría la nueva era del proce-

13 En Europa Continental, estos procedimientos han sido a menudo influenciados por el modelo de procedimiento romano-canónico, sobre esto ver, por ejemplo Van Caenegem, R.C., supra nota 11; FowlerMagerl, L., 'Ordines iudiciarii and libelli de ordine iudiciorum (from the middle of the twelfth to the end of the fifteenth century)' (= Typologie des sources du Moyen Âge occidental 63 A-III.1*), Brepols, Turnhout, 1994; Litewski, W., Der römisch-kanonische Zivilprozess nach den älteren ordines iudiciarii, 2 Vols., Jagiellonian University Press, Kraków, 1999; Van Rhee, C.H., 'Civil Procedure: A European Ius Commune?', European Review of Private Law, 8(4) 2000, pp. 589-611. 
dimiento civil en Europa, afirmó a finales del siglo XIX que aunque el código de procedimiento civil francés no investía al juez francés de poderes de largo alcance en lo relativo a la dirección del procedimiento, tales poderes eran ejercidos en la práctica por él sin base legal en el Código ${ }^{14}$. La referida afirmación hace eco de una observación realizada constantemente por los mismos autores franceses al escribir sobre el procedimiento civil desde la segunda mitad del siglo XIX en adelante, aunque verificar la veracidad de tales afirmaciones requeriría una investigación extensa de la jurisprudencia francesa y de las prácticas judiciales del día a día durante este período, tarea que excede la esfera del presente artículo. La observación de Klein nos concientiza acerca del hecho que la práctica legal y la cultura procedimental son asuntos importantes cuando se trata de establecer las cualidades de un modelo procesal particular ${ }^{15}$. Del mismo modo, esta observación puede dar pie a cuestionamientos tales como, cuánta regulación es efectivamente necesaria en el procedimiento civil y si un código debe ser algo parecido a un manual para el juez y las partes o si debiera restringirse a contener las reglas básicas necesarias para la aplicación del derecho procesal civil. No obstante, la respuesta a estas preguntas, igualmente escapa del alcance del presente artículo.

Tal como se afirmó con anterioridad, el código francés de 1806 sirvió de base a la reforma y codificación del derecho procesal civil en una serie de territorios y países europeos. Frecuentemente estos países o territorios habían sido anexados, o se habían vuelto dependientes del imperio francés antes de la era napoleónica y durante la misma. Varios de estos países son tratados en el presente artículo. En Bélgica por ejemplo, el Código de 1806 se convirtió en ley del territorio al momento mismo de su introducción en 1807, lo cual se debió al hecho de que los Ilamados 'Países Bajos del Sur' o 'Habsburg' fueron anexados al imperio francés en 1795. En los Países Bajos del Norte que fueron anexados a Francia en 1810, el Code de procédure civile fue instaurado en 1811 en la mayoría de las provincias que pertenecen al, hoy en día, Reino ${ }^{16}$. Ginebra, integrado a la República Francesa en 1798, y varias regiones al oeste del

14 El Pro Futuro de Klein, Betrachtungen über Probleme der Civilprocessreform in Oesterreich, Leipzig/ Vienna, Franz Deuticke, 1891, p. 25: 'Dem französischen Rechte ist der Richter in Prüfen, Glauben und Urtheilen eine lebendige Person mit zu achtenden intellectuellen und moralischen Bedürfnissen, nicht ein blutleerer Judicaturapparat, wie sich ihn das gemeine Recht ausgesonnen hat. Diese so unscheinbare Wahrheit [...] erklärt, warum in Frankreich freie Instructionsthätigkeit des Richters ohne besondere gesetzliche Anerkennung bestehen, die allercursorischste Normirung genügen kann.'

15 Cf. También las siguientes citas de Franz Klein: 'Das Gesetz gibt eine Menge Regeln und Vorschriften, die für sich und in ihrer Composition, rein wissenschaftlich beurtheilt, den besten Process darstellen. Aber was aus ihnen in Wirklichkeit wird, darüber entscheiden Jene, welche das Gesetz anwenden: Richter und Anwälte. Von ihnen hängt es ab, ob die gute Saat auch aufgeht.' (Klein, F., supra nota 14, p. 6); '[...] die alten Gedanken saugen den neuen Institutionen die besten Säfte aus, machen sie zu lebensvoller Bethätigung unfähig' (Klein, F., supra nota 14, p. 28); 'Der Richterstand muss da härter werden. So lange man sich bei Entscheidungen über alle strittigen Erstreckungen wie heute von dem in dubiis mitius leiten lässt, ist Alles umsonst' (Klein, F., supra nota 14, p. 79).

16 Algunos territorios del sur, aproximadamente en lo que hoy son las provincias holandesas de NoordBranant y Limburgo, habían sido anexados a Francia en 1795, como resultado, los Códigos Franceses fueron introducidos antes en estos territorios. 
río Rin que fueron incorporadas a la República Francesa desde 1790 en adelante y que actualmente pertenecen a la Alemania moderna -Rheinpreussen, Rheinhessen y Rheinbayern, el Reino de Westfalia y el Gran Ducado de Berg-, son otros ejemplos de territorios donde el código francés entró en vigencia (en el Reino de Westfalia esto sucedió en 1809 y en el Gran Ducado de Berg en 1811) ${ }^{17}$.

Tal como se desprende de las contribuciones al presente artículo, ninguno de los territorios y países mencionados retrocedió a sus prácticas originales ni a sus procedimientos de litigio civil luego de que fuese derrocado el emperador francés en 1813. En todos estos territorios y países, los códigos franceses, incluyendo el Código de Procedimiento Civil, continuaban en vigencia hasta que se hubiese redactado una versión originaria en suelo nacional. Fue Bélgica el país que tardó más en la introducción de un código propio ${ }^{18}$. El Código Francés se mantuvo vigente en este país hasta adentrado el siglo XX, cuando fue reemplazado por el Code judiciaire de 1967, o como es Ilamado en el territorio belga de habla holandesa ${ }^{19}$, el Gerechtelijk Wetboek.

Los Países Bajos fueron más rápidos a la hora de reemplazar el código francés ${ }^{20}$. Luego de que el país se liberara del régimen francés en 1813, se conformó una comisión cuyo propósito, entre otros, fue el de realizar un anteproyecto del Código de Procedimiento Civil holandés. El proceso de codificación tardó un vasto período de tiempo; en 1815 como resultado del Congreso de Viena, los Países Bajos se unieron con lo que hoy es conocido como Bélgica en el Reino de los Países Bajos. En el sur, donde las clases dominantes de habla francesa se encontraban altamente influenciadas por la cultura de Francia -lo cual solo cambiaría en la segunda mitad del siglo XX en lo que atañe a lo que actualmente es Flandes debido a la emancipación de los belgas de habla holandesa- y donde los códigos franceses se habían mantenido en vigencia por un largo período de tiempo en comparación con los territorios del norte, las codificaciones napoleónicas eran vistas como un modelo a seguir para los intentos de nuevas codificaciones. En el norte, por el contrario, regía un modelo -entre ellos el del rey Guillermo I- originalmente destinado a la redacción de códigos puramente holandeses, lo que significaba que el modelo procedimental francés no sería seguido muy de cerca. Finalmente y como resultado de la presión belga -y probable-

17 Van Caenegem, R.C., supra nota 11, p. 93.

18 Van Orshoven, P., 'The Belgian Judicial Code (1967)', en Van Rhee, C.H. (ed.), European Traditions in Civil Procedure, Intersentia, Antwerpen, Oxford, 2005, pp. 97-102.

19 Por razones desconocidas, el idioma holandés hablado en Bélgica es descrito como 'Flamenco' o 'Vlaams'. Esto es muy inusual, sobre todo porque la población de habla francesa de Bélgica 'Volonés' no se refiere a su idioma como 'Volonés' o a alguna expresión similar, tampoco es deseable, puesto que da la impresión de que el holandés es el idioma de una parte de la población mucho más pequeña de lo que de verdad es.

20 Jongbloed, A.W., 'The Netherlands (1838-2005)', en Van Rhee, C.H. (ed.), European Traditions in Civil Procedure, Intersentia, Antwerpen, Oxford, 2005, pp. 69-95. 
mente también porque los abogados holandeses se habían habituado a los códigos franceses durante el largo período de tiempo que tomó la redacción de los códigos holandeses- se presentó un Código de Procedimiento Civil que puede ser calificado como una mala traducción del código francés ${ }^{21}$. Este junto a otros códigos holandeses debían entrar en vigencia en 1831. Esto se pospuso como resultado de lo que los historiadores denominan la 'Revuelta Belga'. Esta revuelta resultó en la separación de los Países Bajos del Sur del Reino de los Países Bajos en 1830 luego de 15 años de unión. Luego, tardó otros 8 años la introducción del Código de Procedimiento Civil holandés en el norte, en esos años se intentó introducir elementos originalmente holandeses al anteproyecto de código, como por ejemplo, la reconvención, regulación que faltaba en la codificación francesa ${ }^{22}$. Finalmente, el 1 de octubre de 1838 varios códigos, entre ellos el Código de Procedimiento Civil holandés, entraron en vigencia.

Ginebra logró introducir su propia codificación procesal con bastante antelación a los Países Bajos. Luego de recuperar su independencia en 1813 y unirse a la Confederación Suiza ${ }^{23}$ en 1814, introdujo el denominado Code Bellot en el año $1819^{24}$. El Código de Ginebra se caracterizó por ser una versión mejorada del código francés. Aunque el modelo procedimental francés influyó en otros lugares de la Confederación Suiza, solo el código de Ginebra lograría convertirse en un modelo de suma importancia fuera de las fronteras suizas. Ejemplo de aquello fue el caso en los Países Bajos, donde algunos de sus elementos fueron incorporados al código de $1838^{25}$. Los

21 Jongbloed, A.W., supra nota 20.

22 Van Rhee, C.H., 'De vordering in reconventie in Nederland en Europa', en Hondius, E.H. et al. (eds), Liber Amicorum Paul Meijknecht. Van Nederlands naar Europees procesrecht?!, Kluwer, Deventer, 2000, pp. 227-242.

23 La influencia francesa en los cantones de habla alemana en Suiza se debió en cierta medida a la importancia de algunos intentos de codificación en cada uno de los Estados alemanes que en parte habían adoptado el modelo de proceso civil francés. Según Paul Oberhammer y Tanja Domej, por ejemplo 'Germany, Switzerland, Austria (ca. 1800-2005)' en C.H. van Rhee (ed.), European Traditions in Civil Procedure, Intersentia, Antwerpen, Oxford, 2005, pp. 103-128, el cantón suizo de Zurich fue influenciado por Hannover y Baden. Estos Estados conocían un derecho procesal civil con elementos del modelo francés. Por el hecho de que Zurich a su vez influenció el procedimiento en otros cantones suizos, algunos elementos franceses se deben haber filtrado en esos cantones. No obstante, al mismo tiempo se debiese recordar que varios cantones de habla alemana fueron más leales a las tradiciones legales comunes de los Estados alemanes (gemeines Recht), en cambio otros cantones han desarrollado una propia tradición procesal doméstica.

24 Se debe señalar, como Paul Oberhammer y Tanja Domej indicaron (supra nota 23), que hasta hace poco, Suiza no tiene ningún código de procedimiento, pero un total de 26 códigos de los distintos cantones.

25 Sin embargo, no se debe exagerar la influencia del Código de Ginebra en los Países Bajos. Sorprendentemente, la opinión predominante en el Parlamento holandés del siglo XIX, fue que Ginebra era un territorio muy pequeño para servir como ejemplo importante. Ver Noordziek, J.J.F., Geschiedenis der beraadslagingen gevoerd in de Kamers der Staten-Generaal over het ontwerp van Wetboek van Burger- 
intentos de codificación en varios de los Estados germanos también se vieron influenciados por el ejemplo de Ginebra ${ }^{26}$. Como consecuencia de aquello, el Código de Ginebra sirvió como un medio adicional para exportar el modelo de procedimiento civil francés.

Los territorios del margen izquierdo del río Rin fueron anexados a Prusia, Bavaria y Hessen-Darmstadt luego de la derrota del emperador francés como resultado del Congreso de Viena. A pesar de ser anexados, dichos territorios no fueron integrados al sistema legal de los estados. Ellos continuaron regidos por el Código de Procedimiento Civil francés hasta la introducción del Reichszivilprozessordnung germano de 1877 en el año 1879, conocido hoy en día como Zivilprozessordnung (ZPO), para todo el Imperio germano, también denominado Segundo Imperio creado en 1871 como resultado de los esfuerzos del 'Canciller de Hierro' Otto von Bismarck. En consecuencia, el derecho procesal francés no servía solo como un ejemplo externo para los intentos de codificación, sino que también, de cierto modo, como un modelo germano interno.

Un ejemplo de proyecto de codificación germana influenciado por el modelo procesal francés fue el Código de Procedimiento Civil del Reino de Hannover del año 1850. Las ventajas del modificado modelo francés del Código de Procedimiento Civil de Ginebra, también fueron reconocidas. En el capítulo sobre los territorios de habla germana ${ }^{27}$. se afirma que la razón principal que conduce a hacer hincapié en el Código de Hannover es la superioridad del Código de Ginebra. El Código de Hannover tiene una perspectiva franco-ginebrina que enfatiza la oralidad y autonomía de las partes. Sin embargo, esto no significa que las características propias de la tradición germana se encuentren ausentes. Por ejemplo, en lo referido al Beweisinterlokut del Código de Hannover ${ }^{28}$.

lijke Regtspleging, Vol. I, Martinus Nijhoff, La Haya, 1885, pp. 4-5. El miembro de la Comisión Redactora A.J. Barthélémy (1764-1832) informó en francés a la Cámara Baja holandesa en los siguientes términos: 'Nous n'avons pas dédaigné toutefois de consulter l'étranger, lorsque nous avons pu en espérer des lumières; c'est ainsi que nous avons distingué le Code de procédure de la République de Genève, nous lui avons même emprunté quelques dispositions, et s'il eût été destiné au service d'un grand État, on pouvait faire plus.' G. Beelaerts van Blokland (1772-1842), miembro del Parlamento Holandés, se sorprendió de que el pequeño tamaño de Ginebra fuera utilizado como argumento para no adoptar sus soluciones de forma más amplia: '[...] ik zou mij niet laten weerhouden door de bedenking, dat hetzelve is gemaakt voor een' kleinen Staat, in bevolking naauwelijks gelijk staande met één van onze arrondissementen; want zoodanige bedenking zou, op zijn best genomen, toepasselijk kunnen zijn op de regtsgedingen voor den hoogen raad; maar in die, welke voor de arrondissementsregtbanken en kantongeregten gebragt worden, zou hetgeen waar, goed en doelmatig is voor één arrondissement, ook waar, goed en doelmatig zijn voor honderd' (Noordziek, J.J.F., supra, pp. 46-47).

26 Oberhammer, P. y Domej, T., supra nota 23.

27 Idem.

28 Idem. 
Además de Hannover, Bavaria y Prusia también presentaron anteproyectos de códigos que seguían de cerca al modelo de procedimiento francés, ello en 1861 y 1864 respectivamente. Eventualmente, Bavaria aprobó un Código de Procedimiento Civil en el año 1869, el cual se basó en el anteproyecto de 1861. Como resultado de ello, el ámbito de aplicación del derecho procesal francés que había sido ejercido en los territorios al oeste de la ribera del río Rin se extendió por todo el país.

La influencia francesa también estaba presente en los diversos anteproyectos de un Código Procesal para toda Germania ${ }^{29}$. El primer anteproyecto fue presentado en 1866, dentro del marco de la Confederación Germana (Deutsche Bund), el cual no fue admitido por Prusia. Luego de que Austria abandonara la Confederación Germana, lo cual llevó a que en 1867 se creara la Confederación Alemana del Norte (Norddeutsche Bund), se presenta un nuevo borrador en el año 1870 dentro del marco de la nueva confederación.

Nuevamente la influencia francesa fue evidente debido al hecho de que este borrador era principalmente una versión revisada del anteproyecto de 1866. Sin embargo, este borrador nunca fue presentado. Un Código de procedimiento para toda Germania solo vería la luz luego de que el Segundo Imperio Germano fuese proclamado en Versalles en 1871. El ministro de Justicia prusiano Leonhardt (1815-1880) quien, entre otros, jugó un rol fundamental tanto en el anteproyecto del Código de Hannover de 1850 - Hannover fue anexado por Prusia en 1866- así como también en el del Código para toda Germania. Por tanto no es una sorpresa que el Código de Hannover haya influenciado y sido consecuencia del siguiente Código Germano de Procedimiento Civil de 1877, esto es, la Reichszivilprozessordnung (ZPO). En algunos aspectos el Código de 1877 poseía una perspectiva aún más francesa que la de su predecesor hanoveriano; por ejemplo, un rasgo germano distintivo del Código hanoveriano, como es el Beweisinterlokut, no estaba presente en el Código Germano de 1877. No obstante, otros elementos del stock germano se mantuvieron, como las reglas sobre participación de terceros en el procedimiento. Por consiguiente, el procedimiento del Código Germano de 1877 puede ser calificado como una combinación de ideas francesas acerca del procedimiento civil y aquellas de la tradición jurídica común de los estados germanos.

El Código de 1877 pronto se convertiría en un modelo que sería seguido por otros países y territorios tales como Austria, Grecia y Japón. Es posible apreciar que el Código de 1877 fue también influyente en Francia ${ }^{30}$. Lo cual se obtuvo como resultado de la reunificación de Francia con Alsacia y Lorena en 1919 -territorio que había sido parte de Alemania desde 1871- y la decisión subsecuente de no derogar el ZPO

\footnotetext{
29 Idem.

30 Wijffels, A., supra nota 12.
} 
en dicho territorio. Como consecuencia de aquello, el Código Germano serviría de ejemplo interno para posteriores reformas al derecho procesal francés, lo cual se vio facilitado por el hecho de que, en Francia, la ZPO estaba destinado a ser superior que el Code de procédure civile de 1806.

\section{Un nuevo modelo procesal: el Código de Procedimiento Civil austríaco de 1895}

Durante la mayor parte del siglo XIX el modelo francés liberal de litigio civil no intervencionista dominó la escena legal europea. Las cosas comenzaron a cambiar y ello se debió, en parte, a las ideas matrices de lo que podría ser denominado como el 'estado de bienestar'. La Zivilprozessordnung austríaca de 1895, introducido en 1898, cuyo anteproyecto diseñado por Franz Klein (1854-1926) se alza como un hito legislativo en el campo del procedimiento civil, siendo reflejo de las nuevas ideas. Fue este código el que cambió la cara del procedimiento civil en Austria sobre la base tanto de conceptos procesales elaborados con anterioridad como también de elementos positivos del procedimiento civil de otros países ${ }^{31}$. Este código serviría de modelo para otros países durante el siglo XX, tal como lo fue el código francés de 1806 durante gran parte del siglo XIX.

Franz Klein, a esa altura ya Privatdozent, explicó de manera sistemática, entre 1890 y 1891, sus ideas acerca del litigio civil en una colección de artículos publicados en el Juristische Blätter, los cuales fueron republicados en su Pro Futuro. Betrachtungen über Probleme der Civilprocessreform in Oesterreich. En mi opinión, hasta el día de hoy y a más de un siglo, esta serie de ensayos constituyen un importante material de consulta para cualquier reformista del procedimiento civil. El propósito de Klein era la realización de la Ilamada 'función social' (Sozialfunktion) de la litigación ci$\mathrm{vi}^{32}$. Esta función social podía ser vista como una reacción contra el ideal liberal del procedimiento característico del siglo XIX, lo cual significó que el litigio no debía considerarse únicamente como un medio para resolver conflictos individuales entre litigantes privados, sino también como un fenómeno que englobaba a la sociedad

31 Sorprendentemente, Klein fue muy positivo en cuanto a la práctica legal francesa, en su opinión, difería de la impresión que un especialista del Código de Procedimiento Civil francés podría dar. Ver, por ejemplo., Klein, F., supra nota 14, pp. 24-25.

32 Klein afirmó que en su tiempo el procedimiento civil austriaco se quedó atrás en comparación con los otros países de Europa: '[...] so sagt uns die Thatsache, dass Oesterreich mit dem Grundsatze der Richterpassivität und der zarten Schonung der Parteisouveränität im continentalen Europa gegenwärtig schon fast allein steht, zweierlei. Einmal, dass die österreichische Gesetzgebung die Verfolgung wichtiger socialer Ziele allzulange ausser Acht gelassen und uns damit von dem politischen und Culturfortschritte ausgeschlossen hat, der in jeder relativ besseren Durchführung jener Postulate gelegen ist. [.... ${ }^{\prime}$ (Klein, F., supra nota 14, p. 23). 
como un todo ${ }^{33}$. El procedimiento civil debía servir a los intereses públicos (Wohlfahrtsfunktion), pero al mismo tiempo debía ser apreciado desde una perspectiva económica, lo cual quería decir, por ejemplo, que uno debía resguardarse el uso del procedimiento civil como un medio para posponer el pago de una deuda o para obtener dinero a una tasa de interés baja ${ }^{34}$.

Esas ideas modernas de Klein pueden ser encontradas en casi todas la páginas de su Pro Futuro, la modernidad de las mismas se ve demostrada en la siguiente cita, en la cual describió el modelo de procedimiento austríaco que pretendía cambiar: ¡iLa juventud se impregna del principio moral de que también hay que ayudar al enemigo en tiempos de necesidad, pero en el proceso es completamente diferente! El proceso es una guerra en la que las partes con odio sombrío, piensan en todos los medios posibles en tratar de destruir al enemigo, para así tener el derecho o razón. No es un conflicto armado, como el duelo, con mezcla de lealtad y nobleza, que despreciaba la explotación de las contingencias adversas que afectaba a uno de ellos, no una batalla en la que la búsqueda de la victoria reprime cualquier otra consideración, cualquier indicio noble debe permanecer en silencio, al punto de estar todo permitido, lo único que importa es ver sangrar silenciosamente al adversario sin la asistencia legal o ética requerida; por así decirlo, una guerra sin Cruz Roja' ${ }^{\prime 35}$. A fin de alterar este enfoque del procedimiento civil como una especie de batalla entre las partes, y de crear un nuevo modelo de procedimiento en el cual fuese reconocida la función social del litigio civil, Klein apuntó a encontrar un nuevo equilibrio entre los poderes del juez y los de las partes. Hace más de cien años, él defendió la idea de que las partes del juicio deben cooperar con el fin de facilitar la toma de decisiones $^{36}$. Klein consideraba una disputa legal como un fenómeno social negativo, por eso es que exigía que el litigio civil fuese rápido, eficiente y barato. Ello resultaría en casos que son resueltos sobre las bases de la verdad sustantiva o de los hechos, esto es, sobre las bases de los hechos ocurridos y no meramente por la verdad fabricada por las partes en la demanda. En consecuencia, desde su punto de vista las partes tenían que cumplir el Ilamado Wahrheitspflicht, que significa el cumplimiento de su obligación de presentar hechos verdaderos al tribunal ${ }^{37}$.

33 Klein hizo la siguiente pregunta retórica: 'Sollte das 'Processeigenthum' stärker als alles sonstige Privateigenthum sein, und muss erst gesagt werden, welches die öffentlichen Interessen sind, mit denen die uns so selbstverständliche schrankenlose Disposition über den Processinhalt collidirt, und was sich dann gerade aus der Eigenthumsanalogie ergibt?' (Klein, F., supra nota 14, p. 17).

34 Ver Fasching, H.W., 'Die Weiterentwicklung des österreichischen Zivilprozessrechts im Lichte der Ideen Franz Kleins', en Hofmeister, H. (ed.), Forschungsband Franz Klein (1854-1926). Leben und Wirken, Manz, Vienna, 1988, pp. 97 y ss, y Van Caenegem, R.C., supra nota 11, p. 97.

35 Klein, F., supra nota 14, p. 39.

36 Por ejemplo, Klein, F., supra nota 14, p. 44: 'Anerkennen wir dann [...] dass das sich souverän Gegenüberstehen der Parteien mit seinen manchen Inconvenienzen nicht durch die 'Processidee' gefordert wird, sondern der Processzweck vielmehr umgekehrt Mitarbeiterschaft beider Parteien fordere.'

37 Klein señaló que si esto fuese diferente, significaría que las partes tenían el poder 'den Richter zu einem irrigen oder doch nur relativ richtigen, beziehungsweise ungenauen Urtheil zu leiten und zu verhalten' (F. Klein, supra nota 14, p. 13). 
Aparentemente, las ideas de Klein se tornaron atractivas dado que fue nombrado Ministerialsekretär del Ministerio de Justicia austríaco el 17 de febrero de 1891, sitio en el cual se le encomendó la tarea de redactar un nuevo código procesal, cuya finalidad sería reemplazar el Allgemeine Gerichtsordnung de $1781^{38}$.

En el Zivilprozessordnung de Klein, el juez estaba a cargo de la duración de pleito y ejercía importantes poderes en el área de la recopilación de datos. El juez estaba facultado a recolectar evidencia de oficio, la cual era evaluada libremente por el tribunal. Una característica interesante e innovadora del Zivilprozessordnung era la división del juicio en una etapa preparatoria escrita y una audiencia preferentemente única ${ }^{39}$.

El Zivilprozessordnung austríaco se volvió muy influyente fuera de Austria, principalmente en el universo de habla alemana. En Alemania las innovaciones austríacas fueron adoptadas en una etapa temprana ${ }^{40}$. Un ejemplo es la Novelle de 1924 del secretario de Justicia alemán Emminger, la cual tuvo por resultado la extensión de los poderes del juez alemán. Ahora, también a este juez se le hizo responsable en lo respectivo a los plazos. Adicionalmente, el juicio fue dividido en una etapa preparatoria y una audiencia oral concentrada. En 1933, se introdujo el Wahrheitspflicht en Alemania.

Sería una exageración proponer que el procedimiento civil austriaco solo influenció al procedimiento civil alemán, y que un proceso similar no se podría advertir en la dirección opuesta. Por el contrario, existen varios ejemplos en los cuales Austria adopta ideas y reglas procesales alemanas. En el presente volumen se evidencia que varios pasajes del Zivilprozessordnung austríaco eran similares o incluso idénticos a las reglas del ZPO alemán. Este proceso de influencia mutua continúa hasta hoy en día, por ejemplo, en lo relativo a la adopción en Austria de reglamentación alemana estricta relativa a la admisibilidad de alegaciones tardías, no obstante el fracaso de dicha adopción. Por consiguiente, parece justificarse el hablar de un modelo o familia austro-germana del procedimiento civil${ }^{41}$, el cual llegó a ser especialmente influyente en otros países, como por ejemplo en los Países Bajos ${ }^{42}$.

38 Sprung, R., 'Der Lebensweg Franz Kleins (24 April 1854 bis 6 April 1926)', en Hofmeister, H. (ed.), Forschungsband Franz Klein (1854-1926). Leben und Wirken, Manz, Vienna, 1988, p. 26.

39 Aparentemente, esta división de la demanda en dos etapas finalmente no fue exitosa, por lo que fue removida del Libro de Estatutos Austríaco en 1983.

40 Oberhammer, P., y Domej, T., supra nota 23.

41 Ver también Habscheid, W.J. (ed.), Das deutsche Zivilprozessrecht und seine Ausstrahlung auf andere Rechtsordnungen, Gieseking, Bielefeld, 1991.

42 Ver Van Rhee, C.H., 'An Unsuccesful Attempt to Modernise Civil Procedure in the Netherlands in the Early Twentieth Century', en Aurea Praxis, Aurea Theoria, Warsaw, 2011, pp. 2031-2051. 
A pesar de que el modelo procesal francés dominó la escena de los Países Bajos, esta situación cambió en la segunda mitad del siglo XIX, lo cual se materializó en los anteproyectos realizados en dicho período ${ }^{43}$. En la segunda mitad del siglo XIX los desarrollos fueron seguidos muy de cerca en el territorio alemán. A comienzos del siglo $X X^{44}$, Austria se convirtió en el foco de atención, esto se evidencia en un anteproyecto de Código de Procedimiento Civil de la Comisión Real conformada en 1911 la cual, en honor a su presidente, se conoció como la Comisión Gratama. Esta comisión propendía a la división del juicio en una etapa preparatoria y una audiencia de juicio, al igual que en Austria, esta también apuntó a la ampliación de los poderes de dirección del proceso que poseía el juez. Lamentablemente, la versión de la Comisión, publicada en 1920, nunca entró en vigencia. Muchas de las sugerencias de la Comisión solo se concretaron a comienzos del siglo XXI, es decir, más de ochenta años después ${ }^{45}$. Heinrich Heine no exageraba cuando afirmó que si el mundo se fuese a acabar, él se establecería en los Países Bajos, porque, según su parecer, allí todo sucedía cincuenta años después que en cualquier lugar del mundo. Y de hecho, en otros lugares del mundo, las innovaciones austro-germanas fueron introducidas con bastante antelación como sucedió en diferentes países de Europa el Este ${ }^{46}$. Esto no es una sorpresa, puesto que varios de dichos países pertenecieron a la Monarquía Austro-Húngara al momento de la promulgación del Código de Klein. Sin embargo, estas innovaciones tuvieron un éxito prematuro en territorios lejanos tales como en Escandinavia, Grecia, Lichtenstein y Zurich, incluso la reforma procesal francesa se vio influenciada por el modelo austro-germano. Tal como se ha mencionado con anterioridad, esto en parte se debió al hecho que Alsacia y Lorena fueron anexadas a Francia en 1919 conservando la ZPO alemana. Un ejemplo de la influencia austríaca en Francia es probablemente el juge de la mise en état ${ }^{47}$. Se ha afirmado que este juez francés fue formado de acuerdo al 'vorbereitende Richter' austríaco. También en lo relativo a los Principios Directores del Proceso (principes directeurs du procès), tratados a continuación, pudo haber existido influencia extranjera en alguna medida, esta vez proveniente de la doctrina alemana, aunque se debe hacer hincapié en que el rol actual de estos principios en Alemania es muy diferente de su rol en Francia.

\footnotetext{
43 Bosch-Boesjes, J.E., Lijdelijkheid in geding. Een vergelijkend onderzoek naar de mate van zeggenschap van de rechter in de civiele dagvaardings- en verzoekschriftprocedure en in administratieve procedures, Kluwer, Deventer, 1991, p. 24.

44 Jongbloed, W., supra nota 20.

45 Jongbloed, W., supra nota 20.

46 Van Caenegem, C., supra nota 11, p. 97.

47 Wijffels, A., supra nota 12.
} 


\section{Codificaciones durante la segunda mitad del siglo XX: el Code judiciaire belga y el nouveau Code de procédure civile francés}

Mientras que el Code de procédure civile francés de 1806 pudo haber perdido su posición como punto central de referencia en el debate procesal internacional a fines del siglo XIX, esto no significó que el código en sí mismo desapareciera del firmamento procesal en aquel momento. Se mantuvo en vigencia tanto en Francia como en Bélgica durante un largo período de tiempo, aunque no sin enmiendas. Como se acaba de afirmar, en Bélgica fue recién reemplazado en la segunda mitad del siglo XX por el Code judiciaire de 1967, mientras que Francia mantuvo el Código de 1806 hasta 1976.

En Bélgica se introdujeron importantes reformas con la promulgación del nuevo Código Judicial ${ }^{48}$. Por ejemplo, el nuevo Código belga formula varios principios procesales generales, respecto a los cuales pudo haber sido influenciado por la discusión francesa sobre principios directores del proceso (principes directeurs du process) que formarían parte del nuevo código procesal francés durante los años setenta. El Código belga también proporciona un modelo común aplicable a todos los tribunales en cada instancia. Además, en comparación con el antiguo Código, las reglas sobre nulidades procesales fueron suavizadas. A la luz de la experiencia de Austria, puede parecer inesperado que el nuevo Código belga sea también muy liberal en cuanto al amplio campo de acción que alcanza la apelación, en la cual pueden ser introducidas nuevas peticiones que no habían sido formuladas en primera instancia. Precisamente esta actitud liberal es actualmente reconocida como uno de los mayores defectos en el nuevo modelo procesal belga, el cual estaba originalmente considerado para ser un éxito. Sin embargo, este régimen liberal tuvo como resultado que el procedimiento de primera instancia no se tomara en serio. Hasta ahora, la legislación belga no ha escogido el enfoque de la legislación alemana, la cual en el 2002 introdujo reformas a modo de reparar este defecto mediante la restricción del proceso de apelación, limitándolo al control de la decisión de primera instancia. Los problemas causados por el Código de 1967 son el resultado del hecho que el legislador belga no tomó una serie de decisiones fundamentales ${ }^{49}$. Además, la cultura procesal belga no cambió como resultado de la introducción del nuevo código. Como consecuencia, las herramientas entregadas por el nuevo código no necesariamente son utilizadas por el juez. Es indispensable una reforma y un primer paso ya se ha dado en esta dirección con la creación de un Consejo Superior de Justicia en 1999, el cual está a cargo de la organización de varios aspectos del poder judicial.

\footnotetext{
Van Orshoven, P., supra nota 18.

49 Idem.
} 
Francia siguió a Bélgica al introducir en 1976 un nuevo Código de Procedimiento Civil luego de un largo período de gestación. Los orígenes del código francés deben ser buscados en la Constitución del General De Gaulle del 28 de septiembre de 1958, la cual es conocida por el hecho de que transfirió muchas facultades desde el Parlamento hacia el Gobierno, lo que también ocurrió en cuanto a la facultad para legislar en el área del procedimiento civil. En consecuencia, la principal fuente del derecho procesal civil en Francia desde 1958 han sido los decretos gubernamentales. Pareciera ser que esta transferencia de facultades fue beneficiosa en lo relativo a las reformas legales en el área del procedimiento civil. En los años cincuenta y posteriormente, el Parlamento Francés fue dominado por abogados, quienes parecen ser reacios en cuanto a la reforma del procedimiento con el fin de no dañar sus propios intereses ni aquellos de sus semejantes.

El objetivo de la reforma procesal francesa era un cambio de cultura procesal. De acuerdo a los escritores de textos franceses, el nuevo código intenta conducirse por un camino intermedio entre el procedimiento adversarial y el inquisitorio. De hecho, esta no es la manera correcta de describir el proceso del nuevo código, el cual apunta a una cooperación legítima entre jueces, abogados y procuradores para beneficio de los litigantes ${ }^{50}$. A modo de ejemplo, un nuevo tipo de juez fue creado a fin de habilitar al tribunal para realizar la dirección del proceso, este es, el juge de la mise en état. Su tarea fue -y es- asegurar una investigación comprensiva y balanceada del caso. El procedimiento previsto por el código es una mezcla de elementos orales y escritos. Otra característica de la reforma fue la formulación de los Ilamados principios directores del proceso (principes directeurs du procès), contenidos en la primera parte del nuevo Código de Procedimiento Civil. Los principios directores del proceso cumplen el objetivo específico de formar el marco para la interpretación del resto del nuevo código. La práctica francesa difiere mucho de la situación de otros países de Europa (por ejemplo, Alemania), en donde gran parte de los principios procesales son considerados por la mayoría de los abogados como meras reflexiones académicas sobre el status quo del proceso civil.

El nuevo código francés está organizado de acuerdo a un plan mucho más racional que el antiguo código de 1806. El nuevo código entrega, en su parte general contenida en su Libro I, un patrón básico del procedimiento civil aplicable a todos los tribunales. Le siguen en su Libro II las normas de aplicación particular a un procedimiento específico en un tribunal determinado. Las materias sobre cuestiones particulares son el tema del tercer libro. Otra característica moderna del nuevo código francés es que su terminología es exacta: las palabras específicas siempre deben tener el mismo significado. Esta racionalización contribuye a la eficiencia del procedimiento.

50 Cadiet, L., 'The New French Code of Civil Procedure (1975)' en C.H. van Rhee (ed.), European Traditions in Civil Procedure, Intersentia, Antwerpen, Oxford, 2005, pp. 49-68. 


\section{Finales del siglo XX: las reglas del procedimiento civil inglés de 1998}

En la visión general que se acaba de dar sobre el desarrollo del derecho procesal civil, Inglaterra no ha sido mencionada. Esto se debe al hecho de que por un largo período de tiempo, el derecho procesal civil inglés fue muy diferente de los sistemas de procedimiento civil en el Continente Europeo. En Inglaterra, la distinción original entre Common Law y Equity era importante también en lo que concierne al proceso civil y la organización de tribunales.

El Common Law era administrado al nivel más alto por las tres Cortes Superiores del Common Law -King's Bench, Common Pleas y Exchequer-. En las cortes del Common Law, las distintas órdenes judiciales determinaban el acceso a la justicia así como también el procedimiento legal que sería aplicable a un caso determinado. El cambio se caracterizó por su lentitud, pero principalmente por ser el resultado de ficciones legales. Hubo una severa distinción entre la etapa preparatoria (pre-trial) y la audiencia única de juicio (trial). Pleading era un arte y fue utilizado como un medio para generar una controversia para ir a juicio. El juicio por jurado era el modelo principal de juicio. En el Common Law, no había un sistema de apelación entendido en un sentido moderno.

La Equity era administrada por la Court of Chancery y por la Sección de Equity de la Court of Exchequer. El Procedimiento de Equity era, hasta cierto punto, comparable con el procedimiento romano-canónico. Por ejemplo, el sistema de discovery utilizado en Chancery -y especialmente, los interrogatorios- estaban relacionados con las positiones del proceso romano-canónico. Lo mismo es aplicable en cuanto a la forma en la cual los testigos eran oídos ${ }^{51}$.

El contacto entre los sistemas procesales en Inglaterra y Europa continental no fue muy intenso, lo cual no quiere decir que dicho contacto estuviese completamente ausente. Se puede mencionar una serie de ejemplos en los cuales se llevó a cabo un intercambio de ideas, por ejemplo en el área de las reglas de la prueba y en lo relativo al procedimiento de las Cortes de Equity, la cual se caracterizaba por su perspectiva Romano-canónica ${ }^{52}$. No obstante, el resultado de estos contactos fue bastante menos pronunciado que el de contactos similares entre los distintos sistemas en el Continente Europeo. Esta situación se mantuvo inalterable durante el siglo XIX, a pesar de que los primeros signos de cambio a este respecto se presentaron tal vez en las Leyes de Administración de Justicia (Judicature Acts) de 1873-1875. En el primer in-

51 Van Rhee, C.H., 'English Civil Procedure until the Civil Procedure Rules (1998)', en C.H. van Rhee (ed.), European Traditions in Civil Procedure, Intersentia, Antwerpen, Oxford, 2005, pp. 129- 60.

52 E.g., Macnair, M., The Law of Proof in Early Modern Equity, Duncker \& Humblot, Berlin, 1999; Van Rhee, C.H., 'Towards a Procedural lus Commune?', en Smits, J. y Lubbe, G. (eds), Remedies in ZuidAfrika en Europa, Intersentia, Antwerpen, 2003, pp. 217-232. 
forme de la Comisión de Administración de Justicia (Judicature Commission), a la cual correspondía la tarea de preparar la nueva legislación, se hace referencia al Código de Procedimiento para el Estado de Nueva York ${ }^{53}$. El redactor de este código, David Dudley Field (1805-1894) tomó algunas de sus ideas del Código de Procedimiento Civil de Louisiana, el cual se basaba en ideas de la tradición continental, principalmente francesas y españolas ${ }^{54}$. Un ejemplo de esta influencia es el documento uniforme para iniciar la litigación (uniform writ of summons), que se tratará a continuación y que fue introducido en Nueva York con más de veinticinco años de antelación a su introducción en Inglaterra. Otro ejemplo y que también se tratará a continuación, es el sistema de pleading el cual cambió desde Issue pleading hacia Fact pleading, también conocido como Code pleading en Nueva York ${ }^{55}$. Los comisionados además se refirieron al procedimiento en la India británica, en donde se promulgó un Código de Procedimiento en el año 1859, así como también a la práctica de los tribunales escoceses. A mi juicio, aunque este problema no ha sido investigado profundamente, pareciera evidente que el Código de la India también fue influenciado por el ejemplo del Código de Field, y es un hecho conocido que la práctica de las cortes escocesas era fuertemente influenciada por ideas romano-canónicas ${ }^{56}$.

Aunque pudo haber existido contacto entre el procedimiento civil inglés y el Continental previamente y durante el siglo XIX, la opinión que los abogados de la tradición anglosajona versus los de la tradición continental tenían el uno del otro en lo relativo a sus sistemas procesales, no era buena. Los abogados ingleses veían como un grave defecto la ausencia del jurado en el litigio civil de la tradición continental, también atacaban el carácter 'inquisitorio' del Procedimiento Civil Continental y la falta de inmediación ${ }^{57}$. Asimismo, los abogados de la tradición continental tenían mu-

53 Judicature Commission, First Report, Parliamentary Papers 1868-1869, Vol. XXV, p. 11.

54 Clark, D.S., 'The Civil Law Influence on David Dudley Field's Code of Civil Procedure', en Reimann, M., (ed.), The Reception of Continental Ideas in the Common Law World (1820-1920), Duncker \& Humblot, Berlin, 1993, pp. 63-87.

55 El sistema de demanda conocido como Code pleading o Fact pleading nos remite a una exposición de los hechos sin arribar a ningún tipo de conclusión legal dejando esa tarea al Tribunal, en tanto el sistema de demanda conocido como Issue pleading tiende a otorgar un marco jurídico al asunto mediante la exposición de los hechos y a la vez, puede entenderse que, en cierto modo, entrega líneas argumentativas entre las cuales optará el Tribunal al momento de sentenciar (N.del. T.).

56 Por ejemplo, el hecho de que el Tribunal de Justicia de la Sesión (Court of Session) escocés ejerciere en su etapa temprana desde una perspectiva romano-canónica, tal como aparece de un texto acerca de los más altos Tribunales escoceses por Finlay, J., Men of Law in Pre-Reformation Scotland (= Scottish Historical Review Monograph 9), Tuckwell Press, East Linton, 2000.

57 Amos, M., 'A Day in Court at Home and Abroad', The Cambridge Law Journal, 1926, pp. 340-349. Ver también Wright, A.C., 'French and English Civil Procedure: A Parallel', Law Quarterly Review, 1926, pp. 327-349, pp. 502-513. En el marco del procedimiento romano-canónico, resulta interesante la defensa de la mediación debido a sus beneficios. Era considerada como un salvavidas de la imparcialidad judicial ya que se pensaba que la percepción del caso por parte del juez sería borrosa por conocer las personalidades de las partes y su comportamiento durante las audiencias. 
chas quejas acerca del modelo procesal inglés. Por ejemplo, en 1828, casualmente uno de los redactores del Código de Proceso Civil holandés (citando a Robert Peel (1788-1850)), anunció públicamente en la Cámara Baja del Parlamento Bicameral de los Países Bajos que Inglaterra no podía servir como un ejemplo para el nuevo código holandés desde 'El Imperio [es decir, Inglaterra] está prácticamente gobernado por una ley cuya existencia está sujeta a la memoria de los abogados, lo cual representa un caos a desentrañar' (pareciera reconfortante para los abogados ingleses pensar que el mismo redactor no previó que el modelo alemán calzara también como un ejemplo, porque 'en gran medida este país [es decir, Alemania] sigue siendo regulado por cancillerías más militares que civiles) ${ }^{58}$.

En el continente las opiniones en cuanto al procedimiento civil inglés cambiaron alrededor de los siglos XIX y XX, lo cual probablemente se debe a las amplias reformas que fueron introducidas en el sistema inglés por las Leyes de Administración de Justicia de 1873-1875. Estas leyes disiparon una de las mayores diferencias entre el proceso civil inglés y el continental ${ }^{59}$. Ejemplo de aquello es el hecho de que las normas de procedimiento inglesas, las cuales hasta ese momento no habían sido codificadas, fueron reunidas en un Anexo adjunto a las Leyes de Administración de Justicia. Según algunos, este Anexo podría ser derechamente descrito como un Código de Procedimiento Civil ${ }^{60}$, aunque se debe considerar inmediatamente que continuaron existiendo diferencias cruciales entre los códigos de procedimiento civil continentales y el Anexo inglés. Aparte de que el Anexo no pretendía ser exhaustivo, otra gran diferencia con los códigos continentales fue que los cambios al Anexo no serían realizados por el Parlamento, sino por un Comité Normativo conformado mayoritariamente por jueces. Fue por este Comité Normativo que las facultades del Parlamento, a este respecto, habían sido delegadas. En esta parte podemos realizar un paralelo interesante con Francia, en donde alrededor de 85 años más tarde, en 1958 se despoja al Parlamento de la facultad para reformar ciertas normas del procedimiento.

En Inglaterra otro desarrollo que convirtió al sistema procesal civil de esa jurisdicción más cercano a ejemplos continentales fue la abolición de la distinción entre Common Law y Equity en el campo del proceso -pero no en el área del derecho sustantivo-, distinción que era desconocida en el Continente Europeo. Para un observador continental moderno, este avance puso fin a los procedimientos del Common Law, el cual, debe admitirse, ya había perdido mucha de su importancia debido a los estatutos previos a 1873. Desde ahora en adelante, las acciones debían interponerse de acuerdo al sistema de citaciones judiciales uniformes, que de cierta forma se asemejaba a las citaciones o convocatorias judiciales continentales. Además, el sistema

\footnotetext{
Noordziek, J.J.F., supra nota 25, pp. 4-5 (Barthélémy).

59 Ver también a Van Caenegem, R.C., supra nota 11, p. 105, p. 110.

60 Van Caenegem, R.C., supra nota 11, p. 104.
} 
de pleading se volvió menos técnico y de cierta manera se asemejó al sistema de pleading que había sido practicado en la Corte de Asuntos Marítimos (Court of Admiralty), la cual poseía un procedimiento con una perspectiva romano-canónica ${ }^{61}$. El nuevo sistema de pleading se hizo conocido como 'fact-pleading', el cual había sido introducido en los Estados Unidos como resultado del Código de Field de 1848. El nuevo procedimiento sería administrado por un Tribunal Superior, mientras que las apelaciones serían oídas por el Tribunal de Apelación.

Del mismo modo, la apelación en sí misma fue una innovación en el sistema inglés, especialmente en los casos conocidos por las Cortes de Common Law antes de 1875, en donde las apelaciones entendidas como una instancia de revisión del caso, eran prácticamente inexistentes hasta la introducción de las Leyes de Administración de Justicia.

Al consultar literatura acerca de la reforma de ley se hace evidente el creciente interés de los abogados Continentales hacia el Procedimiento Civil Inglés a fines del siglo XIX y comienzos del siglo XX. Por ejemplo, Franz Klein comenta el Procedimiento Civil Inglés en su Pro Futuro y menciona algunas materias tales como el desacato de la corte (contempt of court) ${ }^{62}$, el Discovery a través de interrogatorios ${ }^{63} 64$ y la etapa preparatoria del procedimiento (pre-trial $)^{65}$. Incluso la Comisión Holandesa Gratama, cuya labor fue encargarse de la redacción de un borrador del nuevo código procesal holandés a principios del siglo XX, también confesó su interés en el Procedimiento Civil Inglés para los propósitos de su borrador ${ }^{66}$. Aunque, juzgando por este borrador, la influencia inglesa fue mínima, algo que en parte pudo deberse al hecho que la Comisión se vio impedida de visitar Inglaterra con el fin de observar de cerca el Sistema Procesal Inglés en acción, ello debido a que la Primera Guerra Mundial ${ }^{67}$ se encontraba en pleno desarrollo.

El interés continental por el Sistema de Procedimiento Civil Inglés se vio incrementado a fines del siglo XX y a principios del siglo XXI. A modo de ejemplo, en los Países Bajos el Sistema de Procedimiento Civil Inglés es estudiado cuidadosamente por una comisión conformada por tres académicos de derecho escogidos por el gobierno con el objeto de formular ideas que apunten a la innovación del Sistema de

\footnotetext{
Van Caenegem, R.C., supra nota 11, p. 106.

Klein, F., supra nota 14, p. 31.

63 Interrogatorios: Preguntas escritas presentadas por una de las partes que deben ser contestadas por escrito por la contraparte en el marco del conjunto de actos procesales tendientes a la obtención de información y pruebas en una acción judicial, denominado discovery (N. del. T.).

64 Klein, F., supra nota 14, p. 41.

65 Klein, F., supra nota 14, p. 87.

66 Toelichting-Gratama, Algemeene Landsdrukkerij, La Haya, 1920, p. 39.

67 Toelichting-Gratama, supra nota 66, p. 39.
} 
Justicia Civil Holandés ${ }^{68}$. Uno de los propósitos fue cambiar la cultura procesal holandesa. Al menos uno -o más bien tres- de los miembros de esta comisión admira las reglas del nuevo Procedimiento Civil Inglés (CPR). Este renovado interés se debe a las recientes reformas en el Sistema de Justicia Civil Inglesa impulsadas por Lord Woolf (1933), las cuales sirvieron de base para la elaboración de las Reglas del Procedimiento Civil del año 1998. En mi opinión la popularidad de dichas Reglas en el continente se debe a que en parte gracias a ellas el sistema de Procedimiento Civil Inglés se ha acercado como nunca antes a los modelos continentales ${ }^{69}$. En consecuencia, esta situación podría ser una fuente interesante de inspiración para los reformistas continentales.

No parece novedoso que las reformas inglesas fuesen necesarias a fin de reducir la extensa duración y los costos excesivos de la litigación civil. En el pasado también se habían introducido medidas tendientes a producir el efecto de obtener juicios rápidos y menos costosos, pero estas medidas no fueron exitosas. La audiencia preliminar (summons for directions) fue un ejemplo de fracaso de instrumentos para lograr rapidez, el cual fue introducido en 1883.

Una de las razones de por qué las audiencias preliminares (summons for directions) resultaron ser un fracaso, se debió a que no se sancionaba efectivamente a las partes por no respetar la programación fijada como resultado de ellas. La sanción consistía en que los gastos adicionales generados por tal comportamiento procesal debían ser reembolsados. Sin embargo, estos gastos en comparación con los gastos totales de los procedimientos, eran mínimos y no servían como un método de disuasión efectivo para una conducta procesal injustificada.

Otra razón para explicar el fracaso de los instrumentos del procedimiento tales como las audiencias preliminares (summons for directions) fue el hecho de que el juez mostrara una actitud relajada en cuanto a los plazos, puesto que a menudo no amonestaba a las partes por no cumplirlos. Según P. Michalik, esta actitud fue resultado de la disciplina procesal estricta que se respetaba hasta antes de la introducción de las Leyes de Administración de Justicia de 1873-1875. Él afirma 'Se instauró un nuevo espíritu de libertad, el cual se ha asentado firmemente en el corazón del Pro-

68 Esta comisión ha publicado un informe interino: Asser, W.D.H., Groen, H.A. y Vranken, J.B.M. (en cooperación con Tzankova, I.N.), Een nieuwe balans. Interimrapport fundamentele herbezinning Nederlands burgerlijk procesrecht, BJu, La Haya, 2003. Este informe interino se discute desde una perspectiva austríaca por Oberhammer, P., 'Die Aufgabenverteilung zwischen Gericht und Parteien', en Ingelse, P. (ed.), Commentaren op fundamentele herbezinning (= Prinsengrachtreeks 2004-1), Ars Aequi Libri, Nijmegen, 2004, pp. 81- 97. En el 2006, la Comisión publicó su reporte final: Uitgebalanceerd. Eindrapport Fundamentele herbezinning Nederlands burgerlijk procesrecht, BJu, La Haya, 2006.

69 Andrews, N., 'The New English Civil Procedure (1998)' en Van Rhee, C.H. (ed.), European Traditions in Civil Procedure, Intersentia, Antwerpen, Oxford, 2005, pp. 161-184. 
cedimiento Civil Inglés desde aquel entonces. La única excepción a la regla en que la inobservancia de las normas procesales sería perdonada, es aquel caso en el cual la inobservancia de las mismas no podría ser compensada mediante el pago de los gastos. Sin embargo, la convicción general era que la compensación de los gastos era posible casi en todas las situaciones ${ }^{70}$.

Lord Woolf propuso medidas drásticas para cambiar esta situación. En primer lugar, debía ser abordado el carácter adversarial del litigio civil inglés. Antes de la introducción del CPR, el juez inglés era mucho más pasivo que sus pares continentales debido a la estricta observancia de este principio. Esto era efectivo incluso al hacer una comparación con países como los Países Bajos, los que se abstuvieron de introducir el activo juez civil austriaco. Como resultado de las propuestas del lord Woolf esto cambió: La dirección del proceso se convirtió en la clave del Proceso Civil Inglés. De hecho, esto no es tan nuevo como parece, ya que uno de los objetivos de las Leyes de Administración de Justicia del siglo XIX era contar con un juez más activo. No obstante, los medios para alcanzar esta meta son nuevos y efectivos. Actualmente son el juez y los auxiliares de justicia del Tribunal los encargados de asegurar la existencia de un balance entre la complejidad del caso, las técnicas procesales que son usadas y los costos involucrados. Esto se ha facilitado, entre otras cosas, por la creación de tres procedimientos distintos que serán aplicados atendiendo la complejidad de los casos y por el requisito de que la apelación solo puede ser interpuesta con autorización del tribunal ${ }^{71}$. En lo relativo a la apelación, los avances ingleses concuerdan con los avances continentales. Una diferencia importante es que estas restricciones solo se aplican a procesos de tercera instancia en las jurisdicciones occidentales -por ejemplo, Zulassungsrevision en Alemania y Austria-, en cambio en Inglaterra la autorización para apelar ya es requerida en la segunda instancia. No obstante, actualmente en el Continente Europeo pareciera existir una tendencia a reflexionar sobre las limitaciones en lo que dice relación con los litigios de segunda instancia ${ }^{72}$.

El caso del perito compartido constituye otra medida que sirve para probar que el principio adversarial se ha suavizado en Inglaterra. Del mismo modo, al Tribunal

70 Michalik, P., 'Justice in Crisis: England and Wales', en Zuckerman, A.A.S. (ed.), Civil Justice in Crisis. Comparative Perspectives of Civil Procedure, Oxford University Press, Oxford, 1999, pp. 117- 165. A finales del siglo diecinueve Franz Klein, reformista austríaco ya destacaba: 'Die Vorstellung, für Geld sei Alles erlaubt, hat im Processe schon Schaden genug angerichtet [...]' (Klein, F., supra nota 14, p. 80).

71 Antes de la entrada en vigencia del CPR, esta regla solo se aplicaba a las apelaciones ante la Cámara de los Lores (House of Lords, actualmente la Supreme Court del Reino Unido). Esta regla es ahora aplicable a las apelaciones interpuestas ante el Tribunal de Apelación.

72 Para más abundancia en este punto en lo relativo a Alemania, ver, e.g., Heister-Neumann, E., "Große Justizreform' - Der Weg zu einer zukunftsfähigen Justiz', Zeitschrift für Rechtspolitik, 2005, pp. 12-15 (en especial p. 14); Vultejus, U., "Große Justizreform' - Der Weg zu einer zukunftsfähigen Justiz', Zeitschrift für Rechtspolitik, 2005, pp. 99-100; Deiters, M., "Große Justizreform' - Der Weg zu einer zukunftsfähigen Justiz', Zeitschrift für Rechtspolitik, 2005, p. 100. 
se le entregan los medios para influenciar la actitud procesal de las partes, ejemplo de aquello son los protocolos judiciales previos al inicio de la acción judicial, los cuales buscan guiar la actitud adoptada por las partes en los variados tipos de litigios, incluso antes de que el asunto sea sometido al conocimiento del Tribunal. Estos son uno de los medios tendientes a lograr un acuerdo temprano sobre la acción y, si esto no fuese posible, para garantizar que las partes interpongan su demanda completamente informados tanto de las fortalezas como de las debilidades de su caso $^{73}$. Esto está en concordancia con el desarrollo alcanzado en el Continente Europeo, donde la clave de la reforma procesal es la cooperación entre las partes y entre el juez y las partes. Aunque es posible cuestionarse si es que el hecho que el juez se involucre en el proceso pone en duda su imparcialidad, en vista de que podría llegar a involucrarse demasiado en el juicio, se ha afirmado que no existen riesgos al respecto. La participación activa del juez en asuntos procesales no interfiere con su imparcialidad, porque al intervenir en asuntos procesales ex officio, el juez solo lleva a cabo la tarea que le corresponde, apuntando a poner sobre la mesa la verdad genuina, y si esto no es beneficioso para una de las partes, no significa que el juez se ha vuelvo parcial en el sentido de ser prejuiciado.

\section{Conclusión}

En los párrafos anteriores han sido esbozados desarrollos importantes en la historia del procedimiento civil en Europa. En este artículo he puesto énfasis en tres momentos cruciales de esta historia: la entrada en vigencia del Code de procédure civile francés de 1806 en 1807, la entrada en vigencia del Zivilprozessordnung austríaco de 1895 en 1898 y la entrada en vigencia del CPR inglés de 1998 en 1999. En mi opinión, estos momentos son cruciales ya que cambiaron la perspectiva del Derecho Procesal de manera decisiva. El código francés puede ser visto como el símbolo de la sociedad liberal del siglo XIX, con su énfasis en la responsabilidad personal de los litigantes. Los litigantes a los que este código se ha dirigido, por así decirlo, son los 'dueños' de la demanda civil y se consideraba que litigaban el uno contra el otro desde una posición de igualdad. Inicialmente no se creía preferible que las intervenciones de terceros, como por ejemplo la del juez, fueren realizadas con el fin de compensar las desigualdades genuinas. Este código sirvió de influencia para el Derecho Procesal de la mayoría de los Estados europeos, situación que cambió a fines del siglo XIX debido a la influencia de la modificación de las creencias políticas y sociales. El Código de Austria es producto de una nueva era, este apunta a un juez fuerte que está a cargo de los procedimientos y subraya la denominada función social (Sozialfunktion) del litigio civil. Además, este código fue muy influyente en otros Es-

73 Andrews, N., supra nota 59. 
tados europeos, como por ejemplo en Alemania e incluso en los Países Bajos donde el intento de recodificación en base a parámetros austriacos desafortunadamente faIló. En mi opinión, el CPR Inglés podría ser visto como la culminación del desarrollo promovido por el Código de Austria. En la actualidad inclusive el Procedimiento Civil Inglés, con su larga tradición adversarial está dando paso a un tipo de litigio civil que pone cierto énfasis en la cooperación entre las partes y la dirección del proceso por el juez, los que bien podrían ser Ilamados actualmente el 'núcleo central' del Derecho Procesal Civil en Europa y tal vez puede ser visto como un intento de alcanzar un compromiso entre las concepciones social y liberal de los litigios civiles. Los cambios en el Procedimiento Civil Inglés han convertido al sistema inglés en el foco de atención en varios estados de Europa continental. Este desarrollo no significa, por supuesto, que la cooperación y la dirección del proceso se entiendan de la misma manera en Europa, por el contrario, hay distintas interpretaciones sobre el significado práctico de, por ejemplo, el principio del juez activo: los poderes del juez inglés son principalmente procesales mientras que los del juez francés se enfocan tanto en el procedimiento como en el fondo del asunto (hechos y derecho). Los países de habla alemana están muy contentos con sus logros en este contexto, mientras que los otros países, en su opinión, siguen siendo algo reticentes a aceptar que un juez activo alcance prácticamente todos los objetivos del litigio civil con mayor eficacia. Como resultado de ese desarrollo, aunque las diferencias continúan existiendo, en mi opinión uno puede creer que se han reducido en tamaño las antiguas brechas entre las familias procesales en Europa, especialmente la dada entre los países del Civil Law y del Common Law.

Sin embargo, varias advertencias se deben hacer aquí. Primero que todo, incluso dentro de los diversos sistemas procesales, autores, jueces y profesionales no están de acuerdo con las calificaciones que se aplican a sus propios sistemas. Este fue especialmente el caso al momento de la entrada en vigencia del nuevo código en Francia, en donde algunos autores y especialmente jueces describen el sistema procesal francés como acusatorio, otros, especialmente los abogados del sur de Francia reclaman que es inquisitorio, mientras que la mayoría de los autores expresan que el sistema es mixto. Este último punto de vista no difiere mucho de la mirada de que el principio de cooperación es la clave para el Derecho Procesal francés. En segundo lugar, no hay garantía de que la aproximación entre las tradiciones observable actualmente continuará al mismo ritmo, aunque es poco probable que la ya lograda desaparezca por completo. Las garantías son el artículo $6 \mathrm{COEDH}$, la jurisprudencia de la Corte Europea de Derechos Humanos y las actividades al nivel de la Unión Europea. El juez activo, por ejemplo, se mantendrá debido al artículo $6 \mathrm{COEDH}$ y su exigencia de administrar justicia dentro de un tiempo razonable. Después de todo, parece ser que los países sujetos a la jurisdicción de la Corte de Derechos Humanos solo pueden evitar ser sancionados a través de la implementación de un tipo de juez activo. Al mismo tiempo, uno debe darse cuenta que parte de la aproximación que ha ocurrido es solo coincidencia y puede cambiar totalmente. En Austria las reformas que se han introducido en el siglo XX difícilmente son consecuencia de un proceso europeo de 'cir- 
culación de modelos' sino más bien de las experiencias y debates nacionales ${ }^{74}$. De acuerdo con P. Oberhammer y T. Domej, '[c]on todo, en el ámbito de la legislación, en estos días todos hablan de un modo europeo pero a menudo actúan de una manera mucho más nacionalista que en el siglo $\mathrm{XIX}^{\prime 75}$. Un buen ejemplo de un enfoque moderno muy poco europeo se puede observar en Suiza. Allí la reforma legislativa en materia de procedimiento civil se ha introducido sin que el legislador esté preparado para aprovechar las experiencias extranjeras. Los redactores del nuevo Código de Procedimiento Civil para toda Suiza incluso destacan que su Código no está influenciado por modelos extranjeros, sino que simplemente resulta de una 'tradición suiza pura'. Esto no solo es raro ante los ojos de un moderno observador europeo viviendo en un mundo globalizado, sino que incluso habría sido inusual ante los ojos de muchos reformistas del siglo XIX. Tal vez los encargados de reformar el derecho suizo deben tener en cuenta una observación hecha hace casi 200 años, el 7 de febrero de 1828 por miembros del Parlamento de Dotrenge en la Cámara Baja holandesa:

'En la actual Constitución de la gran República Europea, en medio de informes inevitables que involucran a todos los pueblos y gobiernos, un Código de leyes y reglamentos que pretenda aislar a una nación de todas las demás, no convendría y no podría convenir que ella sola, lejos de ser nacional sería por sí misma lo más desastroso, y por lo tanto lo más antinacional que sus legisladores pudieron imaginar haberle entregado ${ }^{176}$.

Además de los peligros antes mencionados en materia de aproximación, hay otros. Uno de ellos es el resultado del período en que los ciudadanos de Europa vivían en un continente dividido, separados entre sí por la Cortina de Hierro. En el antiguo bloque del Este, el juez era muy activo. Este fue el resultado de la creencia que el Estado debe intervenir en la administración de justicia por razones políticas. En consecuencia, después de la desaparición de los gobiernos socialistas en el Este y centro de Europa, los jueces activos se han vuelto muy sospechosos en esta parte del

\footnotetext{
Oberhammer, P., y Domej, T., supra nota 23.

Idem.

76 El discurso de Dotrenge puede encontrarse en Noordziek, J.J.F., supra nota 25, p. 59. El texto original en francés es el siguiente: 'Dans la Constitution actuelle de la grande République Européenne, au milieu des rapports inévitables, qui en lient tous les peuples et tous les Gouvernements, un Code de lois et de règlements qui, isolant une nation de toutes les autres, ne conviendrait et ne pourrait convenir exclusivement qu'à elle seule, loin d'etre national, serait pour elle-même le plus désastreux, et par conséquent le plus anti-national que ses législateurs pourraient imaginer de lui donner.' También citado por Wijffels, A., 'A Phantom Code: The 1830 Code of Civil Procedure for the Kingdom of The Netherlands', en Faure, M., Smits, J. y Schneider, H. (eds), Towards a European lus Commune in Legal Education and Research, Intersentia, Antwerpen/Groningen, 2002, p. 283.
} 
mundo a pesar de que nadie parece darse cuenta, al mismo tiempo, que un enfoque activo es necesario en orden a cumplir con los requisitos del artículo 6 COEDH. Sin embargo, muchos de los abogados en Europa del Este y Europa Central, ahora tienen tendencias hacia una muy marcada autonomía de parte que podría claramente dar como resultado los mismos problemas que se experimentaron al Oeste y que finalmente terminaron con la creencia en la mayoría de los países de Europa Occidental que un juez fuerte y activo puede ser un remedio contra la lentitud y los altos costos. Con el fin de no poner en peligro el cumplimiento del artículo $6 \mathrm{COEDH}$, así como la futura armonización del Derecho Procesal en Europa, por tanto, los abogados de derecho comparado tendrán la misión de demostrar que la cooperación y la dirección del proceso en los litigios civiles no están relacionados con el tipo de juez de los antiguos países socialistas. 


\section{Bibliografía}

Andrews, N., 'The New English Civil Procedure (1998)' en van Rhee, C.H. (ed.), European Traditions in Civil Procedure, Intersentia, Antwerpen - Oxford, 2005, pp. 161-184.

Amos, M., 'A Day in Court at Home and Abroad', The Cambridge Law Journal, 1926, pp. 340-349.

Asser, W.D.H, Groen, H.A. y Vranken, J.B.M. (en cooperación con Tzankova, I.N.), Een nieuwe balans. Interimrapport fundamentele herbezinning Nederlands burgerlijk procesrecht, BJu, La Haya, 2003.

BosCh-BoesJes, J.E., Lijdelijkheid in geding. Een vergelijkend onderzoek naar de mate van zeggenschap van de rechter in de civiele dagvaardings- en verzoekschriftprocedure en Administratieve procedures, Kluwer, Deventer, 1991, p. 24.

Cadiet, L., 'The New French Code of Civil Procedure (1975)' en C.H. van Rhee (ed.), European Traditions in Civil Procedure, Intersentia, Antwerpen - Oxford, 2005, pp. 49-68.

van Caenegem, R.C., 'History of European Civil Procedure', en M. Cappelletti (ed.), Civil Procedure [Vol. XVI International Encyclopedia of Comparative Law, Chapter 2] J.C.B. Mohr, Tübingen [etc.], 1971.

Cappellettı, M. (ed.), Civil Procedure [Vol. XVI International Encyclopedia of Comparative Law, Chapter 2], J.C.B. Mohr, Tübingen [etc.], 1971.

Chorus, J.M.J., 'Het Interim-Rapport en Europa en de wereld', en P. INGELSE (ed.), Commentaren op fundamentele herbezinning (= Prinsengrachtreeks 2004-1), Ars Aequi Libri, Nijmegen, 2004, pp. 25 y ss.

Clark, D.S., 'The Civil Law Influence on David Dudley Field's Code of Civil Procedure', en M. Reimann (ed.), The Reception of Continental Ideas in the Common Law World (1820-1920), Duncker \& Humblot, Berlin, 1993, pp. 63-87.

Deiters, M., "Große Justizreform' - Der Weg zu einer zukunftsfähigen Justiz', Zeitschrift für Rechtspolitik, 2005.

FASCHING, H.W., 'Die Weiterentwicklung des österreichischen Zivilprozessrechts im Lichte der Ideen Franz Kleins', en Hofmeister, H. (ed.), Forschungsband Franz Klein (1854-1926). Leben und Wirken, Manz, Vienna, 1988, pp. 97 y ss,

Faure, M., Smits, J., y Schneider, H. (eds), Towards a European lus Commune in Legal Education and Research, Intersentia, Antwerpen/Groningen, 2002.

Ferrand, F. (ed.), La procédure civile mondiale modélisée, Editions juridiques et techniques, collection Droit et Procédures, Paris, 2005.

Fouchard, $\mathrm{PH}$. (ed.), Vers un procès civil universel? Les règles transnationales de procédure civile de I'American Law Institute, Pantheon-Assas, L.G.D.J. diffuseur, Paris, 2001. 
Fowler-Magerl, L., 'Ordines iudiciarii and libelli de ordine iudiciorum (from the middle of the twelfth to the end of the fifteenth century)' (= Typologie des sources du Moyen Âge occidental 63 A-III.1*), Brepols, Turnhout, 1994;

HaBSCHEID, W.J. (ed.), Das deutsche Zivilprozessrecht und seine Ausstrahlung auf andere Rechtsordnungen, Gieseking, Bielefeld, 1991.

Heister-Neumann, E., "Große Justizreform' - Der Weg zu einer zukunftsfähigen Justiz', Zeitschrift für Rechtspolitik, 2005.

Hofmeister, H. (ed.), Forschungsband Franz Klein (1854-1926). Leben und Wirken, Manz, Vienna, 1988.

Hondius, E.H. et al. (eds), Liber Amicorum Paul Meijknecht. Van Nederlands naar Europees procesrecht?!, Kluwer, Deventer, 2000.

INGELSE, P. (ed.), Commentaren op fundamentele herbezinning (= Prinsengrachtreeks 2004-1), Ars Aequi Libri, Nijmegen, 2004.

Jongbloed, A.W., 'The Netherlands (1838-2005)', en van Rhee, C.H. (ed.), European Traditions in Civil Procedure, Intersentia, Antwerpen - Oxford, 2005, p. 69-95.

Klein, Franz, Betrachtungen über Probleme der Civilprocessreform in Oesterreich, Franz Deuticke, Leipzig/Vienna, 1891.

LindBlom, P.H., 'Harmony of Legal Spheres. A Swedish view on the construction of a unified European procedural law', en European Review of Private Law, 1997, pp. $11-46$

LıTEWSKI, W., Der römisch-kanonische Zivilprozess nach den älteren ordines iudiciarii, 2 Vols., Jagiellonian University Press, Kraków, 1999;

Macnair, M., The Law of Proof in Early Modern Equity, Duncker \& Humblot, Berlin, 1999.

Michalik, P., 'Justice in Crisis: England and Wales', en A.A.S. Zuckerman (ed.), Civil Justice in Crisis. Comparative Perspectives of Civil Procedure, Oxford University Press, Oxford, 1999, pp. 117- 165

NoORDZIEK, J.J.F., Geschiedenis der beraadslagingen gevoerd in de Kamers der StatenGeneraal over het ontwerp van Wetboek van Burgerlijke Regtspleging, Vol. I, Martinus Nijhoff, La Haya, 1885.

Oberhammer, P., 'Die Aufgabenverteilung zwischen Gericht und Parteien', en P. INGelse (ed.), Commentaren op fundamentele herbezinning (= Prinsengrachtreeks 20041), Ars Aequi Libri, Nijmegen, 2004, pp. 81- 97.

Oberhammer, P. y Domes, T. 'Germany, Switzerland, Austria (ca. 1800-2005)' en C.H. van Rhee (ed.), European Traditions in Civil Procedure, Intersentia, Antwerpen Oxford, 2005, p. 103-128,

van Orshoven, P., 'The Belgian Judicial Code (1967)', en C.H. van Rhee (ed.), European Traditions in Civil Procedure, Intersentia, Antwerpen - Oxford, 2005, pp. 97-102. 
Reimann, M. (ed.), The Reception of Continental Ideas in the Common Law World (1820-1920), Duncker \& Humblot, Berlin, 1993,

vaN RHEe, C.H., 'Het burgerlijk procesrecht: een historisch fenomeen met toekomstperspectief', Tijdschrift voor Privaatrecht, 2003, pp. 841-870.

van Rhee, C.H. (ed.), European Traditions in Civil Procedure, Intersentia, Antwerpen Oxford, 2005.

van Rhee, C.H., 'Civil Procedure: A European lus Commune?', European Review of Private Law, 8(4) 2000, pp. 589-611.

van Rhee, C.H. y CoenraAd, L., 'Jurist zonder grenzen: interview met M.L.L.V. Storme', en Th. Veen et al. (ed.), Prominenten kijken om. Achttien rechtsgeleerden uit de Lage Landen over leven, werk en recht (= Pro Memorie. Bijdragen tot de rechtsgeschiedenis der Nederlanden 2004), Verloren, Hilversum, 2004, pp. 155-158.

van Rhee, C.H., 'De vordering in reconventie in Nederland en Europa', in E.H. HonDIUs et al. (eds), Liber Amicorum Paul Meijknecht. Van Nederlands naar Europees procesrecht?!, Kluwer, Deventer, 2000, pp. 227-242.

van Rhee, C.H., 'An Unsuccesful Attempt to Modernise Civil Procedure in the Netherlands in the Early Twentieth Century', en Aurea Praxis, Aurea Theoria, Warsaw, 2011, pp. 2031-2051.

van Rhee, C.H., 'English Civil Procedure until the Civil Procedure Rules (1998)', en C.H. van Rhee (ed.), European Traditions in Civil Procedure, Intersentia, Antwerpen - Oxford, 2005, pp. 129-160.

van Rhee, C.H., 'Towards a Procedural lus Commune?', en Smits, J. y Lubbe, G. (eds), Remedies in Zuid-Afrika en Europa, Intersentia, Antwerpen, 2003, pp. 217-232.

Rouhette, G., 'Sur I'harmonisation du droit du procès civil au sein de I'Union européenne', Justices - Revue générale de droit processuel, 1995.

Smits, J., y Lubbe, G. (eds), Remedies in Zuid-Afrika en Europa, Intersentia, Antwerpen, 2003.

SprunG, R. 'Der Lebensweg Franz Kleins (24. April 1854 bis 6. April 1926)', en HofMEISTER, H. (ed.), Forschungsband Franz Klein (1854-1926). Leben und Wirken, Manz, Vienna, 1988.

Storme, M. (ed.), Rapprochement du droit judiciaire de I'Union européenne/Approximation of Judiciary Law in the European Union, Nijhoff, Dordrecht [etc.], 1994.

Veen, Th. et al. (ed.), Prominenten kijken om. Achttien rechtsgeleerden uit de Lage Landen over leven, werk en recht (= Pro Memorie. Bijdragen tot de rechtsgeschiedenis der Nederlanden 2004), Verloren, Hilversum, 2004.

Vultejus, U., “Große Justizreform' - Der Weg zu einer zukunftsfähigen Justiz', Zeitschrift für Rechtspolitik, 2005 
WiJffels, A., 'A Phantom Code: The 1830 Code of Civil Procedure for the Kingdom of The Netherlands', en M. Faure, J. Smits y H. Schneider (eds), Towards a European Ius Commune in Legal Education and Research, Intersentia, Antwerpen/Groningen, 2002.

WiJfrels, A., 'French Civil Procedure (1806-1975)', en Van Rhee, C.H. (ed.), European Traditions in Civil Procedure, Intersentia, Antwerpen - Oxford, 2005, pp. 25-47.

Wright, A.C., 'French and English Civil Procedure: A Parallel', en Law Quarterly Review, 1926, pp. 327-349.

Zuckerman, A.A.S. (ed.), Civil Justice in Crisis. Comparative Perspectives of Civil Procedure, Oxford University Press, Oxford, 1999. 